\title{
Traumatic Musculotendinous Avulsion of the Flexor Pollicis Longus Tendon: Current Concepts in Strategic Management
}

\author{
Kastanis $G^{1 *}$, Klonos $G^{2}$, Magarakis $G^{1}$, Kapsetakis $P^{1}$, Spyrantis $M^{1}$ and \\ Pantouvaki $\mathbf{A}^{3}$ \\ ${ }^{1}$ Department of Orthopaedic, General Hospital of Heraklion, Venizeleio, Crete, Greece \\ ${ }^{2}$ Department of Emergency, General Hospital of Heraklion, Venizeleio, Crete, Greece \\ ${ }^{3}$ Department of Physiotherapy, General Hospital of Heraklion, Venizeleio, Crete, Greece \\ of Heraklion, Venizeleio, Crete, Greece.
}

Received: August 24, 2020

Published: September 08, 2020

(C) All rights are reserved by Kastanis G.,

et al.

\section{Abstract}

Avulsion amputation injury of the digits of the hand is an uncommon and grave lesion when appeared in the emergency department. Replantation of an amputated digit constitutes a challenge for hand surgeon. This trauma presents a particularly difficult problem to manage because of simultaneous damage of the skin, vessels, nerve and tendons while different surgical techniques have been proposed in international bibliography for the reconstruction of this lesion with a variety of functional results. We report a case after a traffic accident presented with a delay of four hours with an amputation avulsion injury of left thumb in interphalangeal joint with avulsion of flexor pollicis longus from musculotendinous junction and concomitant tear of extensor pollicis longus. The aim of this study is to analyze the current concepts of therapeutic management of this type of lesions.

Keywords: Amputation; Hand; Avulsion; Thumb; Flexor Pollicis Longus Tendon

\section{Introduction}

Acute penetrated traumas involving the hand in emergency department are common injuries and considered a major social and public health problem leading to a physical and mental effect as well as to high costs of initial treatment of its sequels [1]. In USA, injuries of the fingers and hand account to $20 \%$ and are the most affected anatomical sites from work accidents (24\%). It is estimated that the percentage of these specific injuries will be increased, making the modalities of treatment of these lesions of uppermost importance [2]. Among the various lesions of the hand, the most serious and grave lesions constitute traumatic amputation that occurs from high energy trauma. Avulsion amputations injuries of the hand present a particularly difficult problem to management because of simultaneous damage of the skin, vessels, nerve and tendons and different surgical techniques have been proposed in international bibliography for the reconstruction of this lesion with a variety of functional results.

The last years the development of microsurgery created conditions of salvation of amputated hand via replantation and revascularization as the most specific surgical procedure for the treatment of such lesions with success rate to reach $80-90 \%$ [3]. Although the functional outcome of replanted hands will never be equal to that of the contralateral normal healthy one, the target of surgery is to produce major functional, cosmetic and psychological improvements to these patients [4].

\section{Aim of the Study}

The aim of this report is to present a male patient who, after a traffic accident, presented with an amputation injury of left thumb in interphalangeal joint with avulsion of flexor pollicis longus from 
musculotendinous junction and concomitant tear of extensor pollicis longus and to analyze the current concepts of strategic management of this type of lesions.

\section{Case Report}

A 54 year-old man manual labor and current smoker was presented in emergency department after a traffic accident with a delay of four hours. Patient presented with an amputation- avulsion injury of the left thumb (non-dominant hand) (Figure 1a-1c). The past clinical history of the patient was hypertension and diabetes mellitus type I.
The patient was immediately taken to minor operative room in the emergency department. The thumb was disarticulated at interphalangeal joint level. Digital arteries and digital nerves were ruptured at the interphalangeal joint level too. Flexor pollicis longus tendon (FPL) was avulsed from the musculotendinous area and the Extensor pollicis longus (EPL) was ruptured at the metacarpophalangeal joint area (Figure 2). The duration of ischemia was approximately 4 hours. The case was determined as third stage according to Urbaniak classification (Table 1).

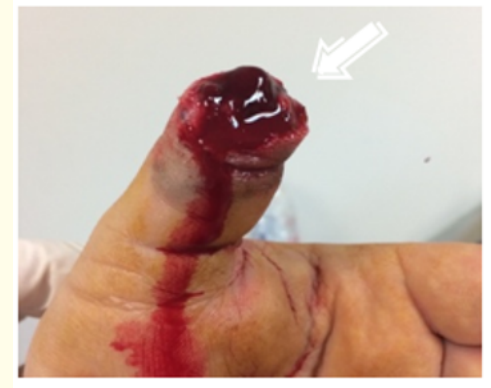

(a)

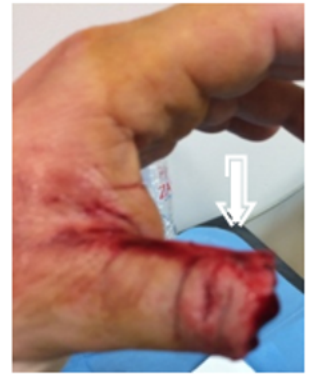

(b)

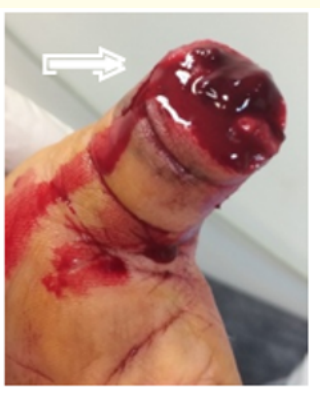

(c)

Figure 1: Amputation of the distal phalanx of the thumb (a-c) at the interphalangeal joint (white arrow).

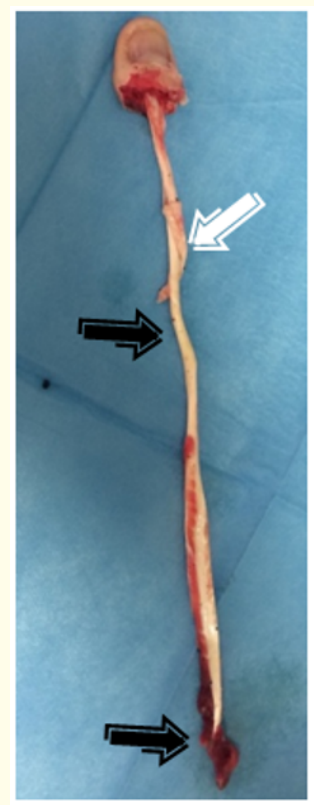

Figure 2: Amputated distal phalange of the thumb, with the two tendons EPL (white arrow), FPL (black arrow) avulsed in musculotendinous area.

\begin{tabular}{|l|c|}
\hline Class I & $\begin{array}{c}\text { Circulation adequate. Standard bone and soft tissue } \\
\text { treatment is sufficient }\end{array}$ \\
\hline Class II & $\begin{array}{c}\text { Circulation inadequate. Vessel repair preserves viabil- } \\
\text { ity permitting immediate or delayed repair of other } \\
\text { tissues }\end{array}$ \\
\hline Class III & $\begin{array}{c}\text { Complete degloving or completed amputation. Judge- } \\
\text { ment is essential, because although a complete ampu- } \\
\text { tation can be revascularised and viability restored, the } \\
\text { potential for function is limited. In degloving injuries, } \\
\text { the potential for useful function exists, but revascu- } \\
\text { larisation is not easy or may not be possible. }\end{array}$ \\
\hline
\end{tabular}

Table 1: Urbaniak classification.

Under digital block, wound debridement and copious irrigation were performed. We suggested to the patient having replantation and revascularization of the amputated phalanges of the thumb and reconstruction of both tendons, considering the fact that the patient was a manual labor, but he refused, so the stump was treated after debridement with skin graft following a slight bone shortening. Two months after injury the patient returned to previous work, was extremely satisfied and had a good hand function (Figure 3a-3d). 


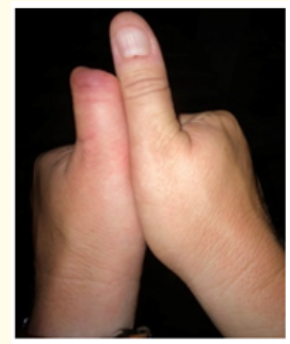

(a)

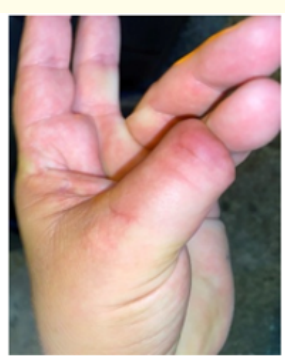

(b)

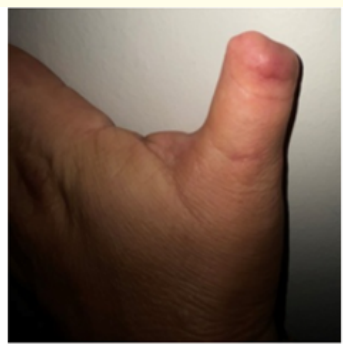

(c)

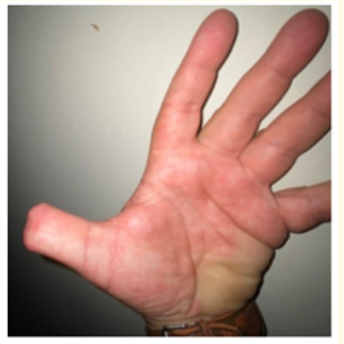

(d)

Figure 3: Functional results in two months after injury (a-d).

\section{Discussion}

Rupture of the musculotendinous unit along its length can appear to five areas: 1) the point of insertion of tendon into bone, 2) the tendon substance, 3) the musculotendinous junction, 4) the muscle belly and 5) the muscle origin [6]. From all five points the weakest link and the highest percentage to present avulsion is bony insertion and musculotendinous junction [7]. Tearing away of FPL is common during avulsion amputations of the thumb and usually appears with rupture of EPL [8]. Thumb amputation is of major importance in relation to the other fingers of the hand, because $40 \%$ of hand function depends on the thumb and therefore replantation and full recovery is the only option [9].

Researchers in international literature recommend many classification systems to provide a more accurate approach to treat these injuries. Urbaniak., et al. (1980) report a classification system that divides these lesions in three classes based on the circulatory condition [5]. Kay., et al. (1989) suggest an alternative classification system in which the amputation injuries are accompanied with or not other skeletal injuries [11]. Adani., et al. (1996) modified the Kay classification adding degloving ring lesions in class IV and separate the complete amputation category into two subgroups based on amputations distal to the flexor digitorum superficialis (FDS) insertion from those proximal to the FDS insertion [11]. The Tamai (1982) classification divides the phalanx into two anatomical zones while Yamano (1985) classifies fingertip amputations regarding to the mechanism and severity of injury [10]. In our department we adopt the Urbaniak classification system because we believe is more practical and ease to perform in such injuries (Table 1).
Avulsion amputations injuries of the thumb are grave lesions because of concomitant destructions of the skin, vessels, nerve, tendons and bones. The goal of treatment is to salvage the digit, maintain functionality and present an esthetic quality. In past times, amputation, local pedicled flaps, abdominal flaps were the treatment of choice. From 1968, with Komatsu and Tamai reporting the first replantation of the thumb until today, replantation and revascularization are the most common techniques which are applied for salvation of an amputated hand [3]. The first step of the treatment of avulsion amputation injuries, is the surgical debridement of trauma. Arterial gap can be filled with arterial transposition or venous graft application. Several hand surgeons suggested different techniques among the revascularization with various functional results (vessels with long vein grafts, venous flow through flaps, or transfer of vessels from adjacent fingers) [12]. Among reconstruction of the avulsion tendons, therapeutic management of flexor and extensor tendons depended on the level of amputation: metacarpophalangeal joint level injuries, the tendon reattachment procedure is preferable for both flexors and extensor, while for amputations at the level of proximal phalange, the tendons transfer and reattachment of them was the most indicated method when the thumb was replanted $[6,13]$.

In literature, the replantation and revascularization techniques reported with a success rate varied from $61.6 \%$ to $96 \%$. Kamarul., et al. (2017), in a retrospective cross-sectional study, present factors (type and level of injury, ischemia, surgical technique, patients demographic factors) which related to amputation and affect the overall survival rate [3]. Although in his references this was not demonstrated, most authors proposed that the type of injury is the most important predictive variable. Two references report that clean-cut 
replanted digits appeared 5.17 times to be viable compared to crush and avulsion injuries [14,15]. This could be explained to the circumstances that clean-cut injuries present minimal trauma to soft tissues, bone, tendons, vessels, nerves while crush and avulsion lesions cause extensive damage with a large zone of injury [14]. Ischemia constitutes another serious factor for viability of the replantation. Dec., et al. (2006), in meta-analysis with 1299 cases, suggest that better outcomes appear in digits salvaged when the surgery is less than 12 hours compared with outcomes when surgery is after 12 hours, while Chim., et al. (2013) report that survival and functional outcomes are not compromised by prolonged ischemia [16]. Nevertheless, ischemia time must be decreased, in order to avoid postoperative cardiac or renal failure [17]. Among the techniques, it was also observed that the survival rate after revascularization was higher than after replantation. Hamilton., et al. (1984) report a significant lower rate of acute complications and failure in revascularized patients when compared with replanted patients $[3,20]$. In our case, the type of trauma was avulsion injury at the interphalangeal joint of the thumb (non-dominant hand). The time of ischemia was 4 hours. The patient refused the replantation and revascularization as a treatment method because he suffered from diabetes mellitus type I and the injury was not in dominant hand. Our limitation is that we couldn't know the result we would have with the replant technique.

Moreover, patient demographic factors (smoking, age comorbidities) are variables which affect survival rates. Waikakul., et al. (2000) report a statistical correlation between the smoking and failure rate. This is due to the vasoconstrictive action of nicotine which affects the vascular supply of the replanted digit [18]. Elderly patients have usually comorbidities, high rate of complications, high rate of arteriosclerosis which can restrict functional walkability in small vessels after anastomosis with poor results $[17,19]$. Our patient was a current smoker (30 cigarettes per day) and suffered from diabetes mellitus type I, two predisposing factors that could lead to failure of surgical techniques.

A major factor that performs an important role in evaluating functional results is psychosocial issues. With regard to pain and depression, it has been reported to have greater influences when disability is evaluated in relation to the functionality of the hand [21]. Sebastin., et al. (2010), in a systematic review, refer to the lack of literature among sufficient data about functional outcomes, and suggest to manage this subject in future references exploring functional utility which determines patients ability to use the re- planted part for daily activities and evaluates if intervention was successful or not [22]. We agree with this opinion because our patient, although he has an amputated thumb, is very satisfied with the final result due to no restrictions in daily activities both in work field and in personal life.

\section{Conclusion}

Avulsion amputation injuries of the thumb are serious and grave lesions and present a particularly difficult problem to management. Given the thumb is responsible for $40 \%$ of hand function, we propose that both replantation and revascularization must be the first option to recreate functionality, independently the factors of the methods. In situations in which microsurgery is not possible, other treatment options should be applied (amputation) as final solution [6].

In the functional outcomes patient's ability to use the affected limb and the psychologically impact from the injury must be estimated, because patient's satisfaction is measured by functional ability in daily activities.

\section{Conflict of Interest}

The authors declare that have no conflict of interest.

\section{Bibliography}

1. De Putter CE., et al. "EFEconomic impact of hand and wrist injuries: health-care costs and productivity costs in a population-based study". Journal of Bone and Joint Surgery American 94.9 (2012): e56.

2. De Jong JP., et al. "The incidence of acute traumatic tendon injuries in the hand and wrist: a 10-year population-based study". Clinics in Orthopedic Surgery 6.2 (2014):196-202.

3. Kamarul T., et al. "Replantation and revascularization of amputated upper limb appendages outcome and predicting the factors influencing the success rates of these procedures in a tertiary hospital: An 8-year retrospective, cross-sectional study". Journal of Orthopaedic Surgery. 26.1 (2017): 1-9.

4. Medling BD., et al. "Replantation outcomes". Clinics in Plastic Surgery 34 (2007): 177-185.

5. Urbaniak JR., et al. "Microvascular management of ring avulsion injuries". The Journal of Hand Surgery American 6 (1981): 25-30.

6. Collins J., et al. "Management of digital tendon avulsion at the musculotendinous junction of the forearm: a systematic review". Hand 7.2 (2012): 134-142. 
7. Boyes HJ., et al. "Flexor-tendon ruptures in the forearm and hand". The Journal of Bone and Joint Surgery 42.4 (1960): 637 646.

8. Stevanovic MV., et al. "Avulsion injuries of the thumb". Plastic and Reconstructive Surgery 87.6 (1991): 1099-1104.

9. Sharma S., et al. "Thumb replantation: A retrospective review of 103 cases". Annals of Plastic Surgery 55 (2005): 352-356.

10. Dadaci M., et al. "Assessment of survival rates compared according to Tammai AND Yamano classifications in fingertip replantation". The Indian Journal of Orthopaedics 50.4 (2016): 384-389.

11. Adani R., et al. "Results of remplantation of 33 ring finger avulsion amputation". Journal of Hand Surgery 38.5 (2013): 947956.

12. Sears ED and Chung KC. "Replantation of finger avulsion injuries: A systematic review of the survival and functional outcomes". The Journal of Hand Surgery American 36.4 (2011): 686-694.

13. Saremi H and Karbalaeikhani A. "Tendon transfer in hand trauma: a case report". Trauma Monthly 17.4 (2013): 401-403.

14. Dec W. "A meta-analysis of success rates for digit replantation". Techniques in Hand and Upper Extremity Surgery 10 (2006): 124-129.

15. Sebastin SJ and Chung KC. "A systematic review of the outcomes of replantation of distal digital amputation". Plastic and Reconstructive Surgery 128 (2011): 723-737.

16. Chim H., et al. "Challenges in replantation of complex amputations”. Seminars in Plastic Surgery 27 (2013): 182-189.

17. Battiston B., et al. "Actualities in big segments replantation surgery". Journal of Plastic, Reconstructive and Aesthetic Surgery 60 (2007): 849-855.

18. Waikakul S., et al. "Results of 1018 digital replantations in 552 patients". Injury 31 (2000): 33-40.

19. Goldner RDUJ. "Replantation. In: Wolfe SWHR, Pederson WC, and Kozin SH (editions) Green's Operative Hand Surgery, 6th edition. Philadelphia: Elsevier Health Sciences (2010): 15851601.

20. Hamilton RB., et al. "Survival factors in replantation and revascularization of the amputated thumb - 10 years experience". Scandinavian Journal of Plastic and Reconstructive Surgery 18 (1984): 163-173.
21. Lindenhovius AL., et al. "Correspondence between perceived disability and objective physical impairment after elbow trauma". Journal of Bone and Joint Surgery American 90 (2008): 2090-2097.

22. Sebastin SJ and Chung KC. "A systematic review of the outcomes of replantation of distal digital amputation". Plastic and Reconstructive Surgery 128 (2011): 723-737.

\section{Assets from publication with us}

- Prompt Acknowledgement after receiving the article

- Thorough Double blinded peer review

- Rapid Publication

- Issue of Publication Certificate

- High visibility of your Published work

Website: https://www.actascientific.com/

Submit Article: https://www.actascientific.com/submission.php

Email us: editor@actascientific.com

Contact us: +919182824667 